\title{
Lung Stereotactic Body Radiotherapy: Single-Center Experience
}

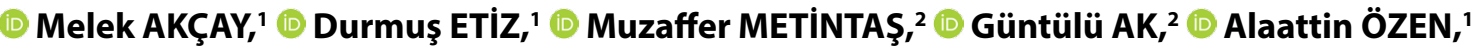 \\ (D) Şenay YILMAZ ${ }^{2}$
}

'Department of Radiation Oncology, Eskişehir Osmangazi University Faculty of Medicine, Eskişehir-Turkey

${ }^{2}$ Department of Chest Diseases, Eskişehir Osmangazi University Faculty of Medicine, Eskişehir-Turkey

\begin{abstract}
OBJECTIVE
To evaluate the results of stereotactic body radiotherapy (SBRT) in early-stage lung cancer, lung metastasis, and recurrent lung cancer.

\section{METHODS}

Fifty-nine cases that underwent lung SBRT due to early-stage lung cancer, lung metastasis, or lung cancer recurrence at our Radiation Oncology Department between 2016 and 2019 were retrospectively evaluated. The factors affecting overall survival (OS) and progression-free survival (PFS) after SBRT were investigated.
\end{abstract}

\section{RESULTS}

After SBRT, the median PFS was 12 (0-40) months, whereas OS was 16 (3-44) months. The median duration of OS and PFS were 15 (5-44) and 12.5 (3-40) months, respectively for early-stage lung cancer, 19 (3-28) and 12 (0-27) months, respectively for recurrent lung cancer, and 14 (5-25) and 8 (5-25) months, respectively, for lung metastasis. During the 16-month median follow-up after SBRT, eight cases (13.6\%) died of cancer, and cancer progressed in 16 cases $(27.1 \%)$. The factors affecting OS after SBRT were age $(\mathrm{p}=0.041)$, KPS $(\geq 80)(\mathrm{p}=0.019)$, and maximum tumor diameter $(\leq 3 \mathrm{~cm})(\mathrm{p}=0.033)$ according to univariate analysis, and KPS $(\geq 80)(\mathrm{p}=0.011)$ and maximum tumor diameter $(>3 \mathrm{~cm})(\mathrm{p}=0.007)$ according to multivariate analysis, and the variables affecting PFS after SBRT were GTV $(\mathrm{p}=0.011)$ and BED10 $(\geq 100)$ $(\mathrm{p}=0.043)$ for the former, and GTV $(\mathrm{p}=0.011)$ for the latter. No patient developed $\geq 3$ radiation pneumonia.

\section{CONCLUSION}

Following lung SBRT, OS was better in younger patients, those with $\geq 80$ KPS or with a tumor diameter of $\leq 3 \mathrm{~cm}$ while PFS was higher in cases with a small GTV volume and those that received BED $10 \geq 100$ radiotherapy dose.

Keywords: Lung cancer; lung metastasis; stereotactic radiotherapy.

Copyright ( $\odot$ 2020, Turkish Society for Radiation Oncology

\section{Introduction}

Lung cancer is the leading cause of cancer-related deaths worldwide.[1] Although the majority of pa- tients have local advanced-stage or metastatic disease at the time of diagnosis, the reported incidence of early-stage non-small-cell lung carcinoma (NSCLC) is expected to increase with the wider use of thorax
Dr. Melek AKÇAY

Eskişehir Osmangazi Üniversitesi Tıp Fakültesi,

Radyasyon Onkolojisi Anabilim Dalı,

Eskişehir-Turkey

E-mail: mcakcay@ogu.edu.tr 
computed tomography (CT) scans.[2] Stereotactic body radiotherapy (SBRT), also known as stereotactic ablative radiotherapy, is a very effective treatment option in patients for whom surgery carries a high risk due to the presence of comorbidities and in those that refuse surgical treatment. SBRT is a conformal technique that can deliver a very high dose (i.e., ablative dose) to the target area in one to five fractions.[3] Lung metastasis is very common in cancer patients. In a study of 1,000 patients, during the autopsy, it was found that $50 \%$ of deaths due to malignancies were associated with pulmonary metastases.[4] In a large series evaluating survival after metastasectomy in patients with lung metastasis, an unexpected 15-year survival rate of $22 \%$ was achieved in stage 4 cases. [5]. Although metastasectomy is considered to be the standard treatment for lung metastasis, surgical treatment is not performed in patients with medical comorbidities, presence of extrathoracic disease, unresectable metastasis, or short-term disease-free survival. SBRT is an effective treatment option in these cases where surgery is not possible.[6]

Recurrence in lung cancer is the main cause of death regardless of tumor histology, cancer stage, and treatment option.[7] In local advanced-stage NSCLC, the rate of locoregional recurrence was reported to be 85\%.[8] Surgery is the first choice for resectable recurrences, with SBRT being recommended by the National Comprehensive Cancer Network NCCN Guidelines in cases where surgery is not indicated.[9]

This study aimed to evaluate 59 cases that underwent lung SBRT at the Radiation Oncology Department of Eskişehir Osmangazi University Faculty of Medicine between 2016 and 2019.

\section{Materials and Methods}

\section{Patients}

A total of 59 cases that underwent lung SBRT at the Radiation Oncology Department of Eskişehir Osmangazi University Faculty of Medicine between 2016 and 2019 were included in this study. The inclusion criteria were being aged $>18$ years, having a Karnofsky Performance Status score (KPS) of $\geq 60$, having completed treatment, and regularly attending the follow-up sessions. In the early-stage lung cancer group, SBRT was not performed in patients with a tumor larger than $5 \mathrm{~cm}$ or T3 mediastinal region invasion, local lymph node or distant metastasis, history of radiotherapy in the planned volume, or ultracentral tumor; thus, these patients were excluded from this study.
The cases with a hilar and/or mediastinal lymph node of $\leq 1 \mathrm{~cm}$ in size with clinically negative Positron Emission Tomography-CT (PET-CT) results, as well as the cases with a $>1 \mathrm{~cm}$ lymph node with a negative pathology result but the presence of abnormal involvement on PET-CT were accepted as having no cancer in nearby lymph nodes (N0). All patients were evaluated at the Chest Diseases Oncology Council, and SBRT was recommended for malignant/recurrent/metastatic cases and patients that were considered to be medically inoperable based on the presence of the first-second forced expiratory volume (FEV1) of $\leq 40 \%$, expected postoperative FEV1 of $\leq 30 \%$, carbon monoxide diffusion capacity of $\leq 40 \%$, hypoxemia/hypercapnia, severe pulmonary hypertension, end-organ damage, diagnosis of diabetes mellitus, severe cerebral, cardiovascular and peripheral vascular disease, and severe chronic heart disease. Biopsy could not be performed in some of the patients that were considered to be medically inoperable due to the risk of morbidity and mortality. After the follow-up thoracic, CT revealed that the mass had grown and hypermetabolic activity was seen on PET-CT, these cases were evaluated in a multidisciplinary manner, and SBRT was planned. In line with the recommendation given in the RTOG 0915 study, for the cases that did not undergo a biopsy, PET-CT was undertaken within eight weeks before SBRT.[10]

\section{Stereotactic Body Radiotherapy}

The planning CT of the patients was obtained as $3 \mathrm{D}$ or $4 \mathrm{D}$ scans. The patients were immobilized in the supine position by raising their arms above their heads on the T-bar/Wingboard specifically designed for lung treatments. Using a Siemens Somatom Definition AS ${ }^{\circledast}$ CT device, a 1-3-mm image was obtained covering the area between the cricoid cartilage and the upper border of the L2 vertebra.

In cases undergoing a $3 \mathrm{D}-\mathrm{CT}$, the scan was performed in normal respiration, deep inspiration, and deep expiration, and the gross tumor volume (GTV) was contoured on all three CTs, and the fusion of all GTVs was achieved. For the planning target volume (PTV), the margins for GTV were set at 0.5 axially and $1 \mathrm{~cm}$ craniocaudally. The external respiratory monitoring system [Real-time Position Management (RPM) System, Varian ${ }^{\circledR}$ Medical Systems, Palo Alto, CA, USA] was used to perform $4 \mathrm{D}$-CT. The RPM system uses an infrared tracking camera that monitors the external marker placed in the upper abdomen of the patient to determine the phases of the respiratory cycle. The breathing cycle is divided into 10 segments (10\% each) 
and consists of expiration and inspiration phases. The number of phases and which phases to be selected in the treatment were determined by the physician during the contouring stage. After GTV contouring in the phases to be used in the treatment, the fusion of all GTVs was obtained, and PTV was obtained by setting the margin to $0.5 \mathrm{~cm}$ in all directions.

In 3D-CT and 4D-CT scans, GTV was contoured using a lung window, and a soft tissue window was also utilized to prevent the inclusion of vascular, atelectasis, or mediastinal and chest wall structures adjacent to GTV. The lungs, heart, main vessels, trachea, ipsilateral bronchial system, skin, ribs, brachial plexus, spinal cord, esophagus, and other organs at risk depending on tumor localization, such as the liver and stomach were contoured.

The most commonly used SBRT scheme is $50 \mathrm{~Gy}$ in 5 fractions. The median radiotherapy dose was 50 (30-60) Gy, the median fraction dose was 10 (4-12) Gy, and the median number of fractions was five (5-13). Normal tissue dose constraints are given in Table 1.

Evaluation of the Treatment Response and Follow-up A thoracic CT was performed within one to three months after radiotherapy, and the PET-CT was undertaken three months after radiotherapy. The patients' responses to treatment were evaluated using a multidisciplinary approach. As recommended in the RTOG 0915 study, a second PET-CT was performed at the end of the first-year follow-up.[10]

\section{Statistical Analysis}

SPSS v. 21.0 for Windows was used in statistical analyses. The Shapiro-Wilk test was conducted to investigate the suitability of the data for normal distribution. Parametric tests were employed for the analysis of the normally distributed data and non-parametric tests for those that did not fit the normal distribution. The independent samples t-test was used for the comparisons between the groups, and the non-parametric Wilcoxon signed-rank test for the evaluation of the pre- and posttest data. The Kaplan-Meier survival analysis was performed to calculate the inter-group survival durations, and the differences were determined using the log-rank statistics. The Cox proportional regression method was utilized to investigate the effects of prognostic variables on survival. Frequency tables were generated to display numbers and percentages, and the data were summarized as mean $\pm \mathrm{SD}$ and median $(\mathrm{Q} 1 ; \mathrm{Q} 3)$ values. $\mathrm{P}<0.05$ was considered statistically significant.

\section{Results}

The median age was 69 (48-85) years. Patient characteristics are summarized in Table 2. Thirty-two of the

Table 2 Patient characteristics

\begin{tabular}{lc} 
Characteristic & n (\%) \\
\hline Age & $\begin{array}{c}\text { Median: } 69(48-85) \\
\text { KPS }\end{array}$ \\
Gender & \\
$\quad$ Female & $11(18.6 \%)$ \\
$\quad$ Male & $48(81.4 \%)$ \\
History of smoking & \\
$\quad$ No & $12(20.3 \%)$ \\
Yes & $47(79.7 \%)$ \\
History of chronic disease & \\
$\quad$ No & $17(28.8 \%)$ \\
Yes & $34(57.6 \%)$ \\
Multiple & $8(13.6 \%)$ \\
\hline
\end{tabular}

KPS: Karnofsky Performance Scale

\begin{tabular}{lccc} 
Table $1 \quad$ Normal tissue dose constraints & & & \\
Tissue & Volume & Volume max (Gy) & Max point dose (Gy) \\
\hline Spinal cord & $<0.25 \mathrm{cc}$ & & \\
& $<0.5 \mathrm{cc}$ & $22.5 \mathrm{~Gy}(4.5 \mathrm{~Gy} / \mathrm{fx}) 13.5 \mathrm{~Gy}(2.7 \mathrm{~Gy} / \mathrm{fx})$ & $30 \mathrm{~Gy}(6 \mathrm{~Gy} / \mathrm{fx})$ \\
Ipsilateral brachial plexus & $<3 \mathrm{cc}$ & $30 \mathrm{~Gy}(6 \mathrm{~Gy} / \mathrm{fx})$ & $32 \mathrm{~Gy}(6.4 \mathrm{~Gy} / \mathrm{fx})$ \\
Skin & $<10 \mathrm{cc}$ & $30 \mathrm{~Gy}(6 \mathrm{~Gy} / \mathrm{fx})$ & $32 \mathrm{~Gy}(6.4 \mathrm{~Gy} / \mathrm{fx})$ \\
Lung (Right\&left) & $1500 \mathrm{cc}$ & $12.5 \mathrm{~Gy}(2.5 \mathrm{~Gy} / \mathrm{fx})$ & $105 \%$ of PTV prescription \\
Lung (Right\&left) & $1000 \mathrm{cc}$ & $13.5 \mathrm{~Gy}(2.7 \mathrm{~Gy} / \mathrm{fx}$ & $105 \%$ of PTV prescription \\
Esophagus, nonadjacent wall & $<5 \mathrm{cc}$ & $27.5 \mathrm{~Gy}(5.5 \mathrm{~Gy} / \mathrm{fx})$ & $105 \%$ of PTV prescription \\
Heart/pericardium & $<15 \mathrm{cc}$ & $32 \mathrm{~Gy}(6.4 \mathrm{~Gy} / \mathrm{fx})$ & $105 \%$ of PTV prescription \\
Great vessels, nonadjacent wall & $<10 \mathrm{cc}$ & $47 \mathrm{~Gy}(9.4 \mathrm{~Gy} / \mathrm{fx})$ & $18 \mathrm{~Gy}(3.6 \mathrm{~Gy} / \mathrm{fx})$ \\
Trachea and ipsilateral bronchus, nonadjacent wall & $<4 \mathrm{cc}$ & &
\end{tabular}


cases had early-stage lung cancer, 21 had recurrent lung cancer, and six had lung metastasis. Of the six cases with lung metastases, two cases were primary laryngeal cancer, two cases were primary breast cancer, and the remaining two cases were primary colorec-

\begin{tabular}{|c|c|}
\hline Characteristic & n (\%) \\
\hline \multicolumn{2}{|l|}{ Diagnosis } \\
\hline Early-stage lung cancer & $32(54.2 \%)$ \\
\hline Recurrent lung cancer & $21(35.6 \%)$ \\
\hline Lung metastasis & $6(10.2 \%)$ \\
\hline \multicolumn{2}{|l|}{ Pre-SBRT biopsy } \\
\hline Yes & $9(15.3 \%)$ \\
\hline No & $50(84.7 \%)$ \\
\hline \multicolumn{2}{|l|}{ Localization } \\
\hline Left lung upper lobe & $11(18.6 \%)$ \\
\hline Left lung lower lobe & $11(18.6 \%)$ \\
\hline Right lung upper lobe & $14(23.7 \%)$ \\
\hline Right lung middle lobe & $6(10.2 \%)$ \\
\hline Right lung lower lobe & $17(28.8 \%)$ \\
\hline \multicolumn{2}{|l|}{ T-stage } \\
\hline T1a & $1(1.7 \%)$ \\
\hline $\mathrm{T} 1 \mathrm{~b}$ & $12(20.3 \%)$ \\
\hline T1c & $10(16.9 \%)$ \\
\hline $\mathrm{T} 2 \mathrm{a}$ & $7(11.9 \%)$ \\
\hline $\mathrm{T} 2 \mathrm{~b}$ & $2(3.4 \%)$ \\
\hline Tumor diameter (maximum) (mm) & Median: 20 (5-54) \\
\hline GTV (cc) & Median: 8.4 (0.2-72) \\
\hline PTV (cc) & Median: 24 (2.3-88.2) \\
\hline
\end{tabular}

SBRT: Stereotactic body radiotherapy; GTV: Gross tumor volume; PTV: planning target volume tal cancer. The tumor characteristics are presented in Table 3. Nine patients had a centrally located lesion. Eleven patients had lesions close to the chest wall.

The median radiotherapy dose was 50 (30-60) Gy, the median fraction dose was 10 (4-12) Gy, and the median number of fractions was five (5-13). The biologically effective dose (BED) was calculated according to the formula of $n \times d(1+d /(\alpha / \beta))$ (n: number of fractions, $\mathrm{d}$ : fraction dose, $\alpha / \beta: 10)$, and the median BED10 was found to be 100 (min: 48, max: 132) Gy.

The first response of the patients was evaluated using the Response Evaluation Criteria in Solid Tumors (RECIST) criteria [11] using the CT performed at one to three months after SBRT. According to these criteria, complete response was seen in four patients (6.8\%), partial response in 41 patients (69.5\%), stable disease in nine patients (15.3\%), and progressive disease in five patients $(8.5 \%)$. In cases with a pre-SBRT PET-CT, the median of the maximum standardized uptake value (SUVmax) was 5, while the post-SBRT median SUVmax was reduced to 2.3. In the 16-month follow-up after SBRT, 51 patients (86.4\%) survived and eight cases (13.6\%) died of cancer. Following SBRT, the median progression-free survival (PFS) was 12 (0-40) months and the overall survival was 16 (3-44) months. Progression was observed in a total of 16 cases (27.1\%) throughout the follow-up period.

The factors affecting the overall survival after SBRT were found to be age ( $p=0.041)$, KPS $(\geq 80)(p=0.019)$, and maximum tumor diameter $(\leq 3 \mathrm{~cm})(\mathrm{p}=0.033)$ according to the univariate analysis, and KPS ( $\mathrm{p}=0.011)$ and maximum tumor diameter $(\mathrm{p}=0.007)$ in the multi-

Table 4 Post-SBRT overall survival and Cox regression results

\begin{tabular}{|c|c|c|c|c|c|c|}
\hline \multirow[t]{2}{*}{ Variable } & \multicolumn{3}{|c|}{ Univariate analysis } & \multicolumn{3}{|c|}{ Multivariate analysis } \\
\hline & OR & $95 \% \mathrm{Cl}$ & $\mathbf{p}$ & OR & $95 \% \mathrm{Cl}$ & $\mathbf{p}$ \\
\hline Age & 1.104 & $1.004-1.215$ & 0.041 & 1.077 & $0.956-1.214$ & 0.222 \\
\hline Gender & 1.440 & $0.177-11.736$ & 0.732 & & & \\
\hline KPS & 0.855 & $0.750-0.975$ & 0.019 & 0.752 & $0.604-0.936$ & 0.011 \\
\hline History of smoking & 0.036 & $0.000-77.067$ & 0.203 & & & \\
\hline History of chronic disease & 0.715 & $0.144-3.551$ & 0.682 & & & \\
\hline Diagnosis (early-stage lung cancer/other) & 7.182 & $0.0864-59.707$ & 0.068 & & & \\
\hline Maximum tumor diameter & 4.587 & $1.135-18.529$ & 0.040 & 0.090 & $0.015-0.522$ & 0.007 \\
\hline GTV (cc) & 1.019 & $0.963-1.079$ & 0.511 & & & \\
\hline PTV (cc) & 1.011 & $0.983-1.039$ & 0.444 & & & \\
\hline Radiotherapy dose & 1.055 & $0.917-1.213$ & 0.454 & & & \\
\hline Fraction dose & 0.845 & $0.614-1.163$ & 0.301 & & & \\
\hline BED & 1.809 & $0.429-7.625$ & 0.420 & & & \\
\hline
\end{tabular}

KPS: Karnofsky Performance Scale; GTV: Gross tumor volume; PTV: Planning target volume; BED: Biologically effective dose 


\begin{tabular}{|c|c|c|c|c|c|c|}
\hline \multirow[t]{2}{*}{ Variable } & \multicolumn{3}{|c|}{ Univariate analysis } & \multicolumn{3}{|c|}{ Multivariate analysis } \\
\hline & OR & $95 \% \mathrm{Cl}$ & $\mathbf{p}$ & OR & $95 \% \mathrm{Cl}$ & $\mathbf{p}$ \\
\hline Age & 1.024 & 0.955-1.099 & 0.502 & & & \\
\hline Gender & 0.736 & $0.205-2.649$ & 0.7638 & & & \\
\hline KPS & 1.031 & 0.960-1.107 & 0.402 & & & \\
\hline History of smoking & 1.684 & $0.524-5.417$ & 0.376 & & & \\
\hline History of chronic disease & 1.925 & $0.237-15.659$ & 0.540 & & & \\
\hline Diagnosis (early-stage lung cancer/other) & 2.139 & $0.736-6.222$ & 0.163 & & & \\
\hline Maximum tumor diameter & 0.436 & $0.154-1.233$ & 0.108 & & & \\
\hline GTV (cc) & 1.048 & 1.011-1.086 & 0.011 & 1.048 & $1.011-1.086$ & 0.011 \\
\hline PTV (cc) & 1.018 & 0.998-1.038 & 0.077 & & & \\
\hline Radiotherapy dose & 0.999 & 0.911-1.096 & 0.982 & & & \\
\hline Fraction dose & 0.864 & $0.679-1.098$ & 0.225 & & & \\
\hline BED & 2.973 & $1.037-8.522$ & 0.043 & 1.974 & $0.616-6.320$ & 0.252 \\
\hline
\end{tabular}

KPS: Karnofsky Performance Scale; GTV: Gross tumor volume; PTV: Planning target volume; BED: Biologically effective dose

variate analysis. The mean age was $67 \pm 7.8$ years in the surviving cases and $72 \pm 7.4$ years in those that died. The results of the Cox regression analysis for the overall survival after SBRT are summarized in Table 4.

The variables affecting PFS after SBRT were GTV (cc) $(\mathrm{p}=0.011)$ and BED10 $(\geq 100)(\mathrm{p}=0.043)$ in the univariate analysis, and GTV (cc) $(\mathrm{p}=0.011)$ in the multivariate analysis. The mean GTV (Q1-Q3) was 6.7 (1.8-14.7) $\mathrm{cc}$ among the surviving patients and 17.3 (4.4-27.8) cc in the mortality cases. Table 5 presents the results of the Cox regression analysis of the variables affecting PFS after SBRT.

During the follow-up, the pre- and post-treatment PET-CT scans were available for 34 cases, for which the low post-SBRT PET-CT tumor SUVmax values were found to be associated with PFS ( $\mathrm{p}=0.011)$. The median (Q1-Q3) PET-CT SUVmax value was calculated as 4.1 (1.3-6.9) in patients that had progressive disease and $2.2(0.3-3.2)$ that did not have progression.

During follow-up, none of the patients had grade $\geq 3$ toxicity.

\section{Discussion}

Approximately $30 \%$ of newly diagnosed NSCLC cases are stage I or II, in which the main treatment is indicated as surgery if there are no contraindications, while SBRT is the primary alternative in cases where surgical resection cannot be performed.[12] The population of patients diagnosed with NSCLC is generally medically inoperable considering the comorbidities they present with. These patients are treated with SBRT, which has been shown to be safe and effective in prospective studies.[13] Some medically inoperable patients have low lung reserves that do not allow for a diagnostic biopsy, given the risk of pneumothorax and even death. In this patient group, SBRT is applied based on radiological/ clinical diagnosis without a biopsy.[14] Furthermore, although metastasectomy is the standard treatment for lung metastases due to different types of cancer, surgery is not possible because of medical comorbidities, extrathoracic disease, and unresectable metastases, and SBRT also presents as a good treatment option in these cases.[15]

Despite the efficacy of external beam radiotherapy (EBRT) and good oncological outcomes of SBRT, intrathoracic recurrences are observed in many cases after radiotherapy.[16] The treatment options for recurrent NSCLC are generally limited. Resection may not be appropriate depending on the location and extent of the recurrence and lung function of the patient. SBRT may be a good treatment option in selected cases after weighing its potential benefits and possible risks. [17] In the 2017 consensus of the American Society of Radiation Oncology, the role of SBRT in salvage therapy were discussed in relation to the following three scenarios after recurrence: conventional fractionated radiotherapy, SBRT, and sublobar resection.[3] In all three scenarios, the quality of evidence from available studies was considered to be low, and personalization of treatment for each patient was recommended. In cases where conventional fractionated EBRT is applied before recurrence, SBRT can be undertaken because it causes radiation damage with different biological mechanisms 
Table 6 Summaries of the studies

\begin{tabular}{|c|c|c|c|c|c|}
\hline Study & $\begin{array}{l}\text { Study } \\
\text { design }\end{array}$ & $\begin{array}{l}\text { Sample } \\
\text { size (n) }\end{array}$ & $\begin{array}{l}\text { Selection } \\
\text { criteria }\end{array}$ & $\begin{array}{c}\text { SBRT } \\
\text { scheme }\end{array}$ & Results \\
\hline Baumann et al. 122009 & Prospective & 57 & $\begin{array}{l}\text { *Medically } \\
\text { inoperable } \\
\text { or those who } \\
\text { refused to } \\
\text { undergo surgery } \\
\text { *Stage I, T1- } \\
\text { T2NOMONSCLC }\end{array}$ & $22 \mathrm{~Gy} \times 3 \mathrm{fr}$ & $\begin{array}{l}\text { *PFS at } 3 \text { years: } 52 \% \\
\text { *OS and CSS at } 1, \\
2 \text {, and } 3 \text { years: } \\
86 \%, 65 \%, 60 \% \text {, } \\
\text { and } 93 \%, 88 \%, 88 \% \text {. } \\
\text { *The estimated } \\
\text { risk of all failure } \\
\text { was increased in } \\
\text { patients with T2 }\end{array}$ \\
\hline Onishi et al. 212007 & Retrospective & 257 & $\begin{array}{l}\text { T1N0M0 or } \\
\text { T2N0M0 primary } \\
\text { lung cancer }\end{array}$ & $\begin{array}{l}\text { *18 to } 75 \text { Gy } \\
\text { (1-22 fr) } \\
\text { *Median BED10: } \\
111 \text { Gy (range, } \\
57-180 \text { Gy) }\end{array}$ & $\begin{array}{l}\text { *For all treatment } \\
\text { methods and } \\
\text { schedules, the local } \\
\text { control and survival } \\
\text { rates were better } \\
\text { with a BED of } 100 \\
\text { Gy or more } \\
\text { compared with less } \\
\text { than } 100 \mathrm{~Gy} \text {. }\end{array}$ \\
\hline Zachary at al. 242015 & Retrospective & 211 & $\begin{array}{c}\text { Biopsy-proven } \\
\text { T1-T2N0M0 NSCLC }\end{array}$ & $\begin{array}{c}* 9-10 \mathrm{~Gy} \times 5 \mathrm{fr} \\
\text { (Central tumors) } \\
* 12 \mathrm{~Gy} \times 4 \mathrm{fr} \\
\text { (Lesions within } 1 \mathrm{~cm} \\
\text { of the chest wall) } \\
* 18-20 \mathrm{~Gy} \times 3 \mathrm{fr} \\
\text { (Peripheral tumors.) }\end{array}$ & $\begin{array}{l}\text { *SUVmax }>3.0 \text { was } \\
\text { associated with } \\
\text { worse survival and } \\
\text { a greater } \\
\text { propensity for local } \\
\text { recurrence and } \\
\text { distant metastasis } \\
\text { after SBRT for NSCLC }\end{array}$ \\
\hline Koshy et al. 302015 & Retrospective & 498 & $\begin{array}{l}\text { T1-T2N0M0 } \\
\text { inoperable } \\
\text { lung cancer }\end{array}$ & $\begin{array}{l}\text { *20 Gy×3 (34\%), } \\
\text { *12 Gy×4 (16\%), } \\
\text { *18 Gy×3 (10\%), } \\
\text { *15 Gy × } 3(10 \%), \\
* 16 \mathrm{~Gy} \times 3(4 \%) .\end{array}$ & $\begin{array}{l}\text { *Higher doses } \\
\text { (>150 Gy BED) } \\
\text { are associated } \\
\text { with a significant } \\
\text { survival benefit in } \\
\text { patients with } \\
\text { T2 tumors. }\end{array}$ \\
\hline Allibhai et al. 32, 2013 & Prospective & 185 & $\begin{array}{c}\text { Medically } \\
\text { inoperable } \\
\text { patients with } \\
\text { early (T1-T2NOM0) } \\
\text { NSCLC }\end{array}$ & $\begin{array}{c}\text { *48 Gy in } 4 \mathrm{fr} \\
(\leq 3 \mathrm{~cm}) \\
{ }^{*} 54-60 \mathrm{~Gy} \text { in } 3 \mathrm{fr} \\
\text { (larger tumors) } \\
{ }^{*} 60 \mathrm{~Gy} \text { in } 8 \mathrm{fr}, \\
50 \mathrm{~Gy} \text { in } 10 \mathrm{fr} \\
\text { (tjmor adjacent } \\
<2 \mathrm{~cm} \text { to mediastinal } \\
\text { structures) }\end{array}$ & $\begin{array}{l}\text { *Tumor size was } \\
\text { associated with } \\
\text { regional failure } \\
\text { and distant failure } \\
\text { *Poorer OS, DFS, } \\
\text { and CSS were } \\
\text { associated with } \\
\text { tumor size. }\end{array}$ \\
\hline Baumann et al. 33, 2009 & Prospective & 138 & $\begin{array}{c}\text { Medically } \\
\text { inoperable } \\
\text { stage I NSCLC }\end{array}$ & $\begin{array}{l}30-48 \text { Gy in } \\
2-4 \text { fractions }\end{array}$ & $\begin{array}{l}\text { *Local failure was } \\
\text { associated with } \\
\text { tumor size, target } \\
\text { definition and } \\
\text { central or pleura } \\
\text { proximity. }\end{array}$ \\
\hline
\end{tabular}


and prevents potential radiation resistance.[18] However, since re-radiotherapy will bring additional toxicity, the benefits and risks should be properly weighed. [19] In cases of recurrence after resection, SBRT is a lung-sparing treatment compared to salvage surgery that usually involves lobectomy or pneumonectomy. However, in these cases, it is necessary to pay attention to toxicity, considering that the lung reserve is reduced after surgery.[20] In the presented series, the median duration of survival was 19 months in patients that underwent SBRT after recurrence.

Although there are many studies showing that local control rates after SBRT are very good, the time interval to evaluate tumor response by imaging methods is not certain.[21,22] In addition, radiographic changes occur in the lung parenchyma after high-dose radiotherapy, and asymptomatic radiographic radiation pneumonia is reported to occur at a rate of $60-100 \%$ in some studies.[22] [18F] -fluoro-2-deoxy-glucose (FDG) PET-CT is frequently used for tumor staging and post-treatment evaluation in early-stage NSCLC. SUVmax is a quantitative measure of tumor glucose metabolism.[23] Some studies have shown an association between pre-treatment SUVmax and overall survival. $[24,25]$ In the current study, the lower PET-CT SUVmax values after treatment was found to be associated with PFS in 34 cases $(\mathrm{p}=0.011)$. FDG PET-CT is often used to assess post-treatment tumor response, but the findings may be difficult to interpret due to FDG uptake in the tumor site caused by radiation-induced pneumonia, inflammation, and fibrosis.[26,27] In addition, it has been shown that SUVmax elevation after SBRT may persist or increase, possibly due to radiation-induced pneumonia and fibrosis.[28]

In a study conducted with 39 patients that underwent SBRT, complete response was reported in 3\% of the patients, partial response in $43 \%$, and stable disease in $54 \%$ using the CT scan undertaken at 1.5 months after SBRT, and when CT was evaluated at the fourth month, these rates were $15 \%, 38 \%$, and $46 \%$, respectively.[29] In the current study, the RECIST evaluation performed by CT within one to three months after SBRT revealed complete response in four patients (6.8\%), partial response in 41 patients $(69.5 \%)$, stable disease in nine patients (15.3\%), progressive disease in five patients (8.5\%).

While the applicability of the BED calculation in large doses per fraction is not clear, Onishi et al., who used this calculation to compare dose and fractionation schemes for SBRT, reported that BED10>100 Gy had a significant oncologic outcomes.[21] Koshy et al. also investigated the contribution of increased dose to the overall survival using the BED calculation. Five different SBRT schemes (cohort ratios) were applied to 489 NSCLC patients with T1-T2N0M0: $20 \mathrm{~Gy} \times 3$ (34\%), $12 \mathrm{~Gy} \times 4$ (16\%), $18 \mathrm{~Gy} \times 3$ (10\%), $15 \mathrm{~Gy} \times 3$ (10\%) and $16 \mathrm{~Gy} \times 3(4 \%)$ fractions. The BED calculation was performed using the linear-quadratic formula of $\alpha /$ $\beta=10$. The patients were divided into high-dose SBRT and low-dose SBRT groups with the BED values being above and below $150 \mathrm{~Gy}$. The calculated median BED was 150 (106-166) Gy. The three-year overall survival rates in high-and low-dose SBRT groups were $55 \%$ and $46 \%$, respectively $(\mathrm{p}=0.03)$.[30] There are also studies showing that BED10<100 dose schemes reduce the local control rate.[21] In the current study, the univariate analysis indicated that PFS was statistically significantly higher in cases with BED $10 \geq 100$ compared to those with BED $10<100(\mathrm{p}=0.043)$.

There are studies evaluating the contribution of tumor size to prognosis. In a retrospective study of 40 patients, the two-year local control rates were $90 \%$ and $70 \%$ for $\mathrm{T} 1$ and $\mathrm{T} 2$ tumors, respectively.[31] In lung SBRT studies, large tumors have been associated with non-local recurrences and poor survival.[32] In the present study, tumor size was associated with the overall survival according to both univariate $(\mathrm{p}=0.033)$ and multivariate $(\mathrm{p}=0.007)$ analyses, and the overall survival was lower in patients with large tumors. However, in the literature, tumor volume appears to be a safer criterion than cross-sectional measurements to evaluate the overall survival and perform better than T-stage in evaluating tumor burden by reflecting tumor shape and biology more accurately.[12,32] In some studies, GTV was found to correlate with local recurrence. $[32,33]$ Higher tumor volume is also considered to reduce the overall survival associated with increased local recurrence.[24] In the current study, GTV was associated with PFS after SBRT in both univariate and multivariate analyses $(p=0.011)$, but no correlation was found between GTV and the overall survival. The studies are summarized in Table 6.

Stereotactic body radiation therapy (SBRT) is an effective and well-tolerated treatment. The high doses used in thoracic SBRT may sometimes cause adverse effects ranging from mild fatigue and transient esophagitis to fatal events, such as pneumonitis or hemorrhage [34]. In this study, during follow-up, none of the patients had grade $\geq 3$ toxicity.

Patients with early-stage lung cancer, recurrent disease and lung metastases were analyzed together and this is the limitation of this study. 


\section{Conclusion}

SBRT is a new and effective treatment option for early-stage lung cancer, lung metastasis, and lung cancer recurrence that cannot be operated. For better local control in cases treated with SBRT, BED10 should be $\geq 100$. The risk of local and distant recurrence should be considered in patients presenting with large tumors.

Peer-review: Externally peer-reviewed.

Conflict of Interest: The authors declare that they have no conflict of interest.

Ethics Committee Approval: Eskişehir Osmangazi University Clinical Research Ethics Committee approval was obtained. (Approval Number: 25403353-050.99-E.102462)

Financial Support: No financial support.

Authorship contributions: Concept - M.A., D.E., M.M., G.A., A.Ö., Ş.Y.; Design - M.A., D.E., M.M., G.A., A.Ö., Ş.Y.; Supervision - M.A., D.E., M.M., G.A., A.Ö., Ş.Y.; Funding M.A., D.E., M.M., G.A., A.Ö., Ş.Y.; Materials - M.A., D.E., M.M., G.A., A.Ö., Ş.Y.; Data collection and/or processing - M.A., D.E.; Data analysis and/or interpretation - M.A., D.E., M.M., G.A.; Literature search - M.A., D.E., M.M., G.A., A.Ö., Ş.Y.; Writing - M.A., D.E., M.M., G.A., A.Ö., Ş.Y.; Critical review - M.A., D.E., M.M., G.A., A.Ö., Ş.Y.

\section{References}

1. Siegel R, Ma J, Zou Z, Jemal A. Cancer statistics, 2014. CA Cancer J Clin 2014;64(1):9-29.

2. Aberle DR, DeMello S, Berg CD, Black WC, Brewer B, Church TR, et al. Results of the two incidence screenings in the National Lung Screening Trial. N Engl J Med 2013;369(10):920-31.

3. Videtic GMM, Donington J, Giuliani M, Heinzerling J, Karas TZ, Kelsey CR, et al. Stereotactic body radiation therapy for early-stage non-small cell lung cancer: Executive Summary of an ASTRO Evidence-Based Guideline. Pract Radiat Oncol 2017;7(5):295-301.

4. ABRAMS HL, SPIRO R, GOLDSTEIN N. Metastases in carcinoma; analysis of 1000 autopsied cases. Cancer 1950;3(1):74-85.

5. Pastorino U, Buyse M, Friedel G, Ginsberg RJ, Girard P, Goldstraw P, et al. Long-term results of lung metastasectomy: prognostic analyses based on 5206 cases. J Thorac Cardiovasc Surg 1997;113(1):37-49.

6. Ricco A, Davis J, Rate W, Yang J, Perry D, Pablo J, et al. Lung metastases treated with stereotactic body radiotherapy: the RSSearch ${ }^{\oplus}$ patient Registry's experience. Radiat Oncol 2017;12(1):35.

7. Jeremić B, Videtic GM. Chest reirradiation with external beam radiotherapy for locally recurrent non-s- mall-cell lung cancer: a review. Int J Radiat Oncol Biol Phys 2011;80(4):969-77.

8. Gressen EL, Werner-Wasik M, Cohn J, Topham A, Curran WJ Jr. Thoracic reirradiation for symptomatic relief after prior radiotherapeutic management for lung cancer. Am J Clin Oncol 2000;23(2):160-3.

9. NCCN Clinical Practice Guidelines in Oncology (NCCN Guidelines ${ }^{\bullet}$ ) Non-Small Cell Lung Cancer Version 2. 2018. Available at: https://www.nccn.org/ professionals/physician_gls/pdf/nscl.pdf. Accessed Mar 13, 2020.

10. Videtic GM, Hu C, Singh AK, Chang JY, Parker W, Olivier KR, et al. A Randomized Phase 2 Study Comparing 2 Stereotactic Body Radiation Therapy Schedules for Medically Inoperable Patients With Stage I Peripheral Non-Small Cell Lung Cancer: NRG Oncology RTOG 0915 (NCCTG N0927). Int J Radiat Oncol Biol Phys 2015;93(4):757-64.

11. Wahl RL, Jacene H, Kasamon Y, Lodge MA. From RECIST to PERCIST: Evolving Considerations for PET response criteria in solid tumors. J Nucl Med 2009;50 (Suppl 1):122S-50S.

12. Baumann P, Nyman J, Hoyer M, Wennberg B, Gagliardi G, Lax I, et al. Outcome in a prospective phase II trial of medically inoperable stage I non-small-cell lung cancer patients treated with stereotactic body radiotherapy. J Clin Oncol 2009;27(20):3290-6.

13. Timmerman R, Paulus R, Galvin J, Michalski J, Straube W, Bradley J, et al. Stereotactic body radiation therapy for inoperable early stage lung cancer. JAMA 2010;303(11):1070-6.

14. Takeda A, Kunieda E, Sanuki N, Aoki Y, Oku Y, Handa H. Stereotactic body radiotherapy (SBRT) for solitary pulmonary nodules clinically diagnosed as lung cancer with no pathological confirmation: comparison with non-small-cell lung cancer. Lung Cancer 2012;77(1):77-82.

15. Boyer MJ, Ricardi U, Ball D, Salama JK. Ablative Approaches for Pulmonary Metastases. Thorac Surg Clin 2016;26(1):19-34.

16. Amendola BE, Amendola MA, Perez N, Wu X, Suarez JB. Local failure after primary radiotherapy in lung cancer: Is there a role for SBRT?. Rep Pract Oncol Radiother 2015;20(6):440-5.

17. Milano MT, Kong FS, Movsas B. Stereotactic body radiotherapy as salvage treatment for recurrence of nonsmall cell lung cancer after prior surgery or radiotherapy. Transl Lung Cancer Res 2019;8(1):78-87.

18. Milano MT, Constine LS, Okunieff P. Normal tissue toxicity after small field hypofractionated stereotactic body radiation. Radiat Oncol 2008;3:36.

19. Milano MT, Mihai A, Kong FS. Review of thoracic reirradiation with stereotactic body radiation therapy: A focus on toxicity risks. Pract Radiat Oncol 2018;8(4):251-65. 
20. Kang KH, Okoye CC, Patel RB, Siva S, Biswas T, Ellis RJ, et al. Complications from Stereotactic Body Radiotherapy for Lung Cancer. Cancers (Basel) 2015;7(2):981-1004.

21. Onishi H, Shirato H, Nagata Y, Hiraoka M, Fujino M, Gomi K, et al. Hypofractionated stereotactic radiotherapy (HypoFXSRT) for stage I non-small cell lung cancer: updated results of 257 patients in a Japanese multi-institutional study. J Thorac Oncol 2007;2(7 Suppl 3):S94-100.

22. Onishi H, Araki T, Shirato H, Nagata Y, Hiraoka M, Gomi K, et al. Stereotactic hypofractionated high-dose irradiation for stage I nonsmall cell lung carcinoma: clinical outcomes in 245 subjects in a Japanese multiinstitutional study. Cancer 2004;101(7):1623-31.

23. Burdick MJ, Stephans KL, Reddy CA, Djemil T, Srinivas SM, Videtic GM. Maximum standardized uptake value from staging FDG-PET/CT does not predict treatment outcome for early-stage non-small-cell lung cancer treated with stereotactic body radiotherapy. Int J Radiat Oncol Biol Phys 2010;78(4):1033-9.

24. Kohutek ZA, Wu AJ, Zhang Z, Foster A, Din SU, Yorke $\mathrm{ED}$, et al. FDG-PET maximum standardized uptake value is prognostic for recurrence and survival after stereotactic body radiotherapy for non-small cell lung cancer. Lung Cancer 2015;89(2):115-20.

25. Sasaki R, Komaki R, Macapinlac H, Erasmus J, Allen P, Forster K, et al. [18F]fluorodeoxyglucose uptake by positron emission tomography predicts outcome of non-small-cell lung cancer. J Clin Oncol 2005;23(6):1136-43.

26. Vahdat S, Oermann EK, Collins SP, Yu X, Abedalthagafi M, Debrito P, et al. CyberKnife radiosurgery for inoperable stage IA non-small cell lung cancer: 18Ffluorodeoxyglucose positron emission tomography/ computed tomography serial tumor response assessment. J Hematol Oncol 2010;3:6.
27. Bollineni VR, Widder J, Pruim J, Langendijk JA, Wiegman EM. Residual ${ }^{18}$ F-FDG-PET uptake 12 weeks after stereotactic ablative radiotherapy for stage I nonsmall-cell lung cancer predicts local control. Int J Radiat Oncol Biol Phys 2012;83(4):e551-e5.

28. Hoopes DJ, Tann M, Fletcher JW, Forquer JA, Lin PF, Lo SS, et al. FDG-PET and stereotactic body radiotherapy (SBRT) for stage I non-small-cell lung cancer. Lung Cancer 2007;56(2):229-34.

29. Mohammed N, Grills IS, Wong CY, Galerani AP, Chao $\mathrm{K}$, Welsh R, et al. Radiographic and metabolic response rates following image-guided stereotactic radiotherapy for lung tumors. Radiother Oncol 2011;99(1):18-22.

30. Koshy M, Malik R, Weichselbaum RR, Sher DJ. Increasing radiation therapy dose is associated with improved survival in patients undergoing stereotactic body radiation therapy for stage I non-small-cell lung cancer. Int J Radiat Oncol Biol Phys 2015;91(2):344-50.

31. Dunlap NE, Larner JM, Read PW, Kozower BD, Lau CL, Sheng K, et al. Size matters: a comparison of T1 and T2 peripheral non-small-cell lung cancers treated with stereotactic body radiation therapy (SBRT). J Thorac Cardiovasc Surg 2010;140(3):583-9.

32. Allibhai Z, Taremi M, Bezjak A, Brade A, Hope AJ, Sun A, et al. The impact of tumor size on outcomes after stereotactic body radiation therapy for medically inoperable early-stage non-small cell lung cancer. Int J Radiat Oncol Biol Phys 2013;87(5):1064-70.

33. Baumann P, Nyman J, Lax I, Friesland S, Hoyer M, Rehn Ericsson S, et al. Factors important for efficacy of stereotactic body radiotherapy of medically inoperable stage I lung cancer. A retrospective analysis of patients treated in the Nordic countries. Acta Oncol 2006;45(7):787-95.

34. Thompson M, Rosenzweig KE. The evolving toxicity profile of SBRT for lung cancer. Transl Lung Cancer Res 2019;8(1):48-57. 